\title{
Part 3 - Cardiac Death in Athletes Implementation of a High Quality, Low Cost, Pathophysiologic Screening Exam
}

\author{
Timothy E. Paterick ${ }^{1 *}$, Naila Choudhary ${ }^{2}$, Krishnaswamy Chandrasekaran ${ }^{3}$, A. Jamil Tajik ${ }^{5}$, and Jim Seward ${ }^{4}$ \\ ${ }^{1}$ Professor of Medicine, Director of Noninvasive Imaging, University of Florida College of Medicine, Jacksonville, FL, USA \\ ${ }^{2}$ Cardiology, Fellow, University of Florida, College of Medicine, Jacksonville, FL, USA \\ ${ }^{3}$ Professor of Medicine, Mayo College of Medicine, Rochester, MN, USA \\ ${ }^{4}$ Professor of Adult and Pediatric Cardiology, Emeritus Nasseff Professor of Cardiology, Mayo Clinic, Rochester MN, USA \\ ${ }^{5}$ Professor of Cardiology, Pediatrics and Adult Congenital Heart Disease, Aurora St. Luke's Medical Center, Milwaukee WI, USA
}

Received: June 25, 2015; Accepted: November 09, 2015; Published: December 31, 2015

*Corresponding author: Timothy E. Paterick, Professor of Medicine, Director of Noninvasive Imaging, University of Florida College of Medicine, Jacksonville FL, USA; Email: tpaterick@gmail.com

\section{Individualize}

Risk must be individualized in an athletic population with diverse activity profiles. An optimal test should meet and exceed present day screening criteria [4]; address variable mechanical, structural and electrical pathobiology [5]; emphasize prognostication (cause-and-effect), not disease detection [6]; use rule out principles [7] to positively define normal and definitively rule out imminent risk of SCD [8].

\section{High Quality}

Essential criteria for quality include: eliminate false positives and false negatives $[5,7]$; prioritize pathophysiology $[5,9]$, causality [10-12], simplicity [13-15], inductive reasoning [16], and "essentialism" [17, 18].

\section{Cost-effectiveness(Cost versus Price)}

It is import to understand the relationships between cost and effectiveness [19]. It is tempting to make decisions about selection of a screening test based on cost minimization, which is only reasonable if the tests are comparable and the clinical outcomes are the same. This is rarely the case --- for example when testing a simple binary assessment between normal and abnormal risk state one might assume that both ECG and echocardiography are superficially similar, but in reality they are markedly different with respect to the sensitivity (rule-out testing) and specificity (rule-in testing) of Pathophysiologic risk [7, 20, 21]. Absolute cost comparisons are unreliable because the test characteristics and demands are so extremely variable [19].

Cost is the amount paid to deliver the product while price is the actual amount of money required to use the product and all the necessary collateral services. The best solution is a substantial reduction in price while prioritizing quality and efficiencies and reducing procedural inefficiencies [19].For example, the cost of ECG is low, $(\approx \$ 0)[22]$ however, the price is prohibitively high because of the low prevalence of diseased athletes and the large number of false-positive and false negative tests [1, 23-29]. Both cost and price of a complete echocardiogram is prohibitively high (e.g., \$427 Medicare to $>\$ 2,275$ ) [30].The cost of a limited echocardiogram is much lower (e.g.,\$10 to $\$ 75$ ) [24, 31, 32], but it does not focus upon the essential features pertinent to athletic screening to determine risk [29, 32, 33]. Small hand held devices have a certain degree of cost effectiveness, [24] but have a high price because this technology currently is incapable of obtaining or quantifying emergent physiologic data.

A logical solution to this dilemma is an essential, focused echocardiogram designed to obtain small numbers of related pathophysiologic data[28] and maximize cost-effectiveness [19]. Practice expenses are further reduced by selection of point-ofcare ultrasound, remote exam rooms, limited documentation, cloud storage and reduction of costly services [28]. The cost of a focused echo cannot mirror the cost of a limited echo, СРT (93308), because the components and services used are substantially different. The essential, focused screening emphasizes the essentials of simplicity [15, 34-36]:assurance of normal and rule-out of abnormal.

Significant cost efficiencies require explicit design features [2, $19,37]$ : results of the test must correlate with result [38, 39] and the outcome managed by change in management. Testing a low risk population mandates the use of fewer resources [28, 40];focus on prognostication, and not diagnosis [6]; ECG and traditional echo cardiographic models are deemed ineffective [28]; nonessential data are excluded $[1,2,18,27,29,41]$; use of lower cost point-of-care ultrasound devices [42, 43]; aggressively reduce acquisition time $(\approx 10$ minutes) $[43,44]$; emphasize causality [2, $5,9,13,28,34,43,45]$; and prioritize the confirmation of normal and there-by rule out the rare abnormal [7].

Additional novel efficiencies include open-access ordering 
$[21,46]$, remote location testing $[21,28,43,47]$ and computerassisted decision-making [48-50].

\section{Open Access Echocardiography}

Is defined as services ordered by a designated health care provider without pre-test assessment by experts $[21,46]$. The athletic population represents the essence of normal, which does not justify the expense of pretest experts [21]. Open access and computer-assisted decision-making allow the user to prioritize referral and alleviate unnecessary expenses $[29,51,52]$

\section{Remote Location Echocardiography}

$[42,43,47]$ is defined as an echocardiographic exam performed outside of a medical facility, which translates into a significant cost savings [42] by reducing the cost of services [28].

\section{Computer Assisted Data Interpretation and Decision- Making}

A human-computer data interpretation interface is predicted to become an all-purpose tool for navigating, manipulating and understanding biological systems $[6,36,45]$. There is convincing evidence that whenever we can assist human judgment with technology, we should at least consider it [49]. The American Society of Echocardiography has prioritized the implementation of computer-assisted interpretation of echocardiographic data by 2020 [53]. This directive is based on the premise that for a wide range of general prediction problems, easy-to-implement computer-based software is as reliable as and typically more reliable than, human expert interpretation [48-50, 54]. Immediate on-site test interpretation $[6,42,49,53]$ and automated quality assurance assist appropriate triage [16, 34, 35, 47]. Elective use of web-based physician assistance enhances accuracy and reduces cost [47]. Computer assisted multi-feature systems biology markedly lowers the incidence of false positives, increases access and reproducibility $(96 \%)[43,55,56]$, lowers cost, and increases efficiencies [9, 37, 43].

An essential, focused echocardiogram meets and exceeds the criteria of an ideal pre-participation screening exam [4].
We propose a new and stronger pathophysiologic-based echocardiographic screening exam that optimizes cost and maximizes effectiveness by focusing on the nuances of systems medicine and wellness [57].

\section{Prediction Requires Causality [58]}

Questions that motivate most health science prediction studies are not associative, but causal in nature. For example, we would ask, what is the cause of the death in an athlete, rather than what was the death associated with? Causality requires some knowledge of the data-generating processes; causality cannot be computed from population data alone, or from the distributions that govern the data [11]. Associations alone can never prove causality, but can show you where to look. Associations infer beliefs or probabilities under static conditions, while causality measures beliefs under changing conditions [58] Table 1.

One cannot substantiate claims of causality from associations alone, even at the population level --- behind every causal conclusion there must be some causal assumption that is not testable in observational studies [11]. For example both diastolic dysfunction and abnormal ECG patterns are predictive features of a cardio myopathy; diastolic dysfunction satisfies the definition of a causal feature, and the ECG is a consequence of a disease process.

\section{Prevention: Influence of Causality and Prediction}

Currently the benefits, outcomes, and cost-effectiveness of prevention in athletes remain unresolved [3, 72]. Prediction and prevention are not synonymous, but are co-dependent on causality [57]. An essential, focused screening echo exam is designed to predict an individual's pathophysiologic state, while prevention is modifying and monitoring changes related to disease management [10-12, 73].

In the athletic community there have been three ECG based prevention trials, one positive [22] and two negative [27]. These publications contain controversial interpretations, content,

Table 1: Definition of Invariant Causal Relationships (i.e., Causal-and-Effect)[12].

\begin{tabular}{|c|c|c|c|c|}
\hline Phenomenon & Definition & Observation & $\begin{array}{l}\text { Echocardiographic } \\
\text { Pathophysiology }\end{array}$ & Reference \\
\hline Contiguity & $\begin{array}{l}\text { Cause and Effect must } \\
\text { remain contiguous in time } \\
\text { and space }\end{array}$ & $\begin{array}{l}\text { Cause (input) must be } \\
\text { simultaneously and equally } \\
\text { reflected in Effect (output) }\end{array}$ & $\begin{array}{l}\text { Gradations of diastolic dysfunction } \\
\text { evolve contiguously with effect. } \\
\text { States of causal data mirror the } \\
\text { status of the risk state. }\end{array}$ & {$[38,59-62]$} \\
\hline Succession & $\begin{array}{l}\text { Cause must occur prior to the } \\
\text { Effect }\end{array}$ & $\begin{array}{l}\text { Cause occurs before the } \\
\text { appearance of Effect. Causal } \\
\text { features can be observed in } \\
\text { the pre-clinical or emergent } \\
\text { phase of a disease. }\end{array}$ & $\begin{array}{l}\text { Causal mechanical, structural and } \\
\text { electrical features overlap and } \\
\text { grow in number and intensity in } \\
\text { succession with the expression } \\
\text { of Effect. Small numbers of highly } \\
\text { related causal data best define the } \\
\text { status of a physiologic state. }\end{array}$ & $\begin{array}{l}{[5,9,54,63-} \\
66]\end{array}$ \\
\hline $\begin{array}{l}\text { Constant } \\
\text { Conjunction }\end{array}$ & $\begin{array}{l}\text { Constant union between } \\
\text { Cause and Effect }\end{array}$ & $\begin{array}{l}\text { Change in Cause must be } \\
\text { mirrored in Effect of a } \\
\text { disease and vice versa }\end{array}$ & $\begin{array}{l}\text { Worsening, improvement or } \\
\text { bidirectional change of a disease } \\
\text { state (Effect) is equally mirrored by } \\
\text { the state of a Causal module }\end{array}$ & [67-71] \\
\hline
\end{tabular}


conclusions, and associations [10, 74]. In these epidemiologic studies both prediction and prevention were founded on epidemiologic associations, and not causality [5, 10, 11, 75]. The prediction of risk in athletes requires a measurable pathophysiologic risk profile and treatment strategy and not merely an assumed inevitability [3, 10-12]. Current prevention is thwarted by an emphasis on tests better suited for disease diagnosis $[5,7,10,73]$.

\section{Today}

Today most decisions are made subjectively based on insufficient knowledge and resources. Transformative quantitative pathophysiologic risk profiling has the capacity to substantially improve the quality and accuracy of a disqualification decision [16, 34]. Recommendations for disqualification and eligibility are discussed in the $36^{\text {th }}$ Bethesda Conference [51]. This consensus-based document is extensive and far beyond the scope of an essentially, focused screening test. One of the most revealing attestations in the 36th Bethesda Conference is the term "gray zone"[51], which highlights the fact that there is considerable overlap between normal and abnormal cardiovascular remodeling. A usable pre-participation exam must eliminate the "gray zone"[51, 76] and emphasize normal versus pre-emergent disease [8]. The essentially, focused echo exam does this using diastolic Doppler data.

\section{Tomorrow: Monumental Transformation}

The basic strategy must be to screen healthy athletes to ensure they are not at risk. Medicine is about to undergo a transformation which will change the healthcare system. We will demystify complex disease processes by: (1) providing deep insights into disease processes; (2)individualize risk; (3) define cause-and-effect relationships; (4) initiate pathophysiologic based disease prevention;(5) transform healthcare metrics [57]; and (6) markedly increase the quality and lower the cost of healthcare [17].

There are two inherent challenges that will consume time and resources:(1) the design of a global, integrated system; and (2) ensuring the system incorporates ethical, social, legal, regulatory and economic values [5, 57]. There are a number of features that will assist the transformation: (1)medicine will be looked upon as an informational science, which provides an intellectual framework for dealing with complex medical problems; (2) diseases are redefined as perturbed networks; (3) digital devices will quantify multi-feature risk; (4) causality will be essential to prediction and prevention; and (5) life-long health is maintenance of a measured cascade of wellness. Illness will be defined as a loss of multi-feature regulatory capacity [5]: the inability to adequately respond to internal, environmental and/ or lifestyle factors. Instead of treating a consequence of disease, healing will be defined as treatment of causality $[10,11]$ and restoration of normal regulatory capacity [57].

\section{Practical Implications}

An essential, focused echocardiographic screening exam should take 10 minutes and requires sonographers who with computer assistance, are responsible to interpret and delineate primary, associated, and "incidental" findings that are apparent, or become apparent while obtaining images [28]. Sonographers are responsible for recognizing a predefined list of pathophysiologic data in a specific clinical setting within their scope of practice. A physician's interaction falls specifically within the regular duties of a supervising physician. An essential, focused screening exam is a logical extension of a physician's utilization of evidencebased medical care. The physician will be considered respondent superior for the sonographer team and will therefore have a legal duty to monitor the program to ensure quality and accuracy [11].

\section{Limitations}

The greatest challenges to the use of clinical systems biology screening is predicted to be the inertia of change [77], the entrenched notion that athletic restriction improves outcomes [3], the huge volume of conflicted literature on athletic screening $[3,29,51]$, and unfamiliar nuances of $21^{\text {st }}$ century network medicine [57]. In spite of these challenges computer assisted systems biology is still predicted to markedly transform every aspect of medicine within a decade.

"Ideas (as presented in this manuscript) can change the world --- but only when coupled with influence ---, the ability to change hearts, minds and behavior (Quote: Muhammad Yunus, Nobel Pease Prize Winner (back cover [77]))."

\section{Conclusion}

Sudden cardiac death in an athlete cannot be considered an event that begins with and ends with a catastrophic event. Rather, it should be thought of in the context of a cascade of pathophysiologic events. The presence of symptoms, associated risk factors, and overt image features has been documented to be insensitive and unreliable indicators of risk. Structural and electrical cardiovascular diseases typically evolve through a sequence of causal preclinical pathophysiologic perturbations. A small subset of primary electrical cardiac diseases may be the exception. An essential pre-participation screening focuses on validating wellness and the exclusion of abnormal causal pathophysiology. It is proposed to be the highest quality, lowest cost means of detecting and managing the risk of sudden death in an individual athlete.

Nearly all events attributed to sudden cardiovascular death in athletes have validated pathophysiologic features, which can be used to confirm wellness and rule out risk Table 2 . The exam should take no more than 10 minutes. On site data interpretation can be complemented by computer-assisted intelligence. An essential, focused echocardiographic exam markedly lowers cost, while simultaneously assuring highest quality pre-participation athletic screening.

Essentialism is not about how to get more things done, it's about how to get the right things done. It doesn't mean doing less for the sake of less. It's about making the wisest possible investment in time and energy in order to operate at the highest point of contribution by doing only what is essential $[18,78]$. Screening should not be used as a definitive diagnostic or 


\begin{tabular}{|l|l|}
\hline \multicolumn{2}{|l|}{ Table 2: Essentials of a High Quality, Low Cost Athletic Screening Exam. } \\
\hline Test Type & Focus \\
\hline History and Pretest Data & Asymptomatic personal and family history. Normal blood pressure, heart rate, weight and height \\
\hline $\begin{array}{l}\text { Multi feature Functional Physiology focused on } \\
\text { Causality }\end{array}$ & $\begin{array}{l}\text { Unequivocal normal physiology (Rule out Abnormal) } \\
11 \text { data features }\end{array}$ \\
\hline Hemodynamics & $\begin{array}{l}\text { Normal Pulmonary artery pressure; } \\
\text { Normal abdominal aorta physiology }\end{array}$ \\
\hline Structural Disease & $\begin{array}{l}\text { Normal Proximal Coronary Arteries; Normal cardiac chambers, myocardium, valves and great } \\
\text { vessels } \\
3 \text { essential views }\end{array}$ \\
\hline Cost-Effective Infrastructure & $\begin{array}{l}\text { Markedly Lower Cost } \\
\text { Open Access; Focused Exam; Remote Site; Computer-User Interpretation; Cardiology backup and } \\
\text { referral only if necessary }\end{array}$ \\
\hline Final & $\begin{array}{l}\text { Binary Conclusion: } \\
\text { Unambiguous Normal and Rule-out Principal }\end{array}$ \\
\hline
\end{tabular}

management tool, but a means of identifying the state of a small portfolio of pathophysiologic features, which assure normal and rule-out pre-clinical risk that could be life threatening.

There should be a high degree of trepidation in applying medical management to an asymptomatic, overtly healthy person who is designated by any test as having a potentially life threatening condition. The first essential is to fully document the authenticity of the finding, the magnitude of risk and the desires of the young athlete and entrusted guardians. Ultimately an impartial, trained physician must formulate a disciplined medical opinion, which forms the basis for subsequent decisionmaking. The greatest challenge lies in the continued acceptance of ill designed decisions and tests. The medical community must share differing views openly without falling victim to ridicule for not honoring the past. This manuscript opens a discussion about creating a norm based on pathophysiologic cause-and-effect.

\section{References}

1. Redfield MM, Rodeheffer RJ, Jacobsen SJ, Mahoney DW, Bailey KR, Burnett JC Jr. Plasma brain natriuretic peptide to detect preclinical ventricular systolic or diastolic dysfunction: a community-based study. Circulation. 2004;109(25):3176-3181.

2. Douglas PS. Justifying echocardiography: the role of outcomes research in evaluating a diagnostic test. J Am Soc Echocardiogr. 1996;9(4):577-581.

3. Link MS, Estes NA, 3rd. Sudden cardiac death in the athlete: bridging the gaps between evidence, policy, and practice. Circulation. 2012;125(20): 2511-2516.

4. Lewis GH, Sheringham J, Kalim K, Crayford T. Mastering Public Health: A Guide to Examinations and Revalidation. New York: Oxford University Press; 2008.

5. Loscalzo J, Barabasi AL. Systems biology and the future of medicine Wiley Interdiscip Rev Syst Biol Med. 2011; 3(6):619-627.

6. Carr N. The Glass Cage: Automation and Us. 1st Ed. New York: W. W. Norton \& Company Inc; 2014.

7. Lee WC. Selecting diagnostic tests for ruling out or ruling in disease: the use of the Kullback-Leibler distance. Int J Epidemiol. 1999;28(3):521525.

8. Eagle KA, Ginsburg GS, Musunuru K, Aird WC, Balaban RS, Bennett
SK, et al. Identifying patients at high risk of a cardiovascular event in the near future: current status and future directions: report of a national heart, lung, and blood institute working group. Circulation. 2010;121(12):1447-1454.

9. Barabasi AL, Gulbahce N, Loscalzo J. Network medicine: a networkbased approach to human disease. Nat Rev Genet. 2011;12(1):56-68.

10. Lucas RM, McMichael AJ. Association or causation: evaluating links between "environment and disease". Bulletin of the World Health Organization. 2005; 83(10 AN - PMC2626424): 792-795.

11. Pearl J. Causal inference in statistics: An overview. Statistics Surveys. 2009; 396-146.

12. Selhon J. Models of Causation and Tools for Causal Inference. UC Berkeley [updated; cited]; Available from: http://sekhon.berkeley. edu/papers/causality.pdf.

13. Hood L. Systems biology and p4 medicine: past, present, and future. Rambam Maimonides Med J. 2013;4(2): e0012.

14. Two's Company, Three is Complexity. Neil Johnson e. Oxford, England: Oneworld; 2007.

15. Siegel A, Etzkorn I. Simple: Conquering the Crisis of Complexicity. New York: Hachette Book Group; 2013.

16. Coderre S, Mandin H, Harasym PH, Fick GH. Diagnostic reasoning strategies and diagnostic success. Med Educ. 2003;37(8):695-703.

17. Regalado A. We Need a Moore's Law for Medicine. [updated 2013 Sep 3; cited 2015]; Available from: http://www.technologyreview.com/ news/518871/we-need-a-moores-law-for-medicine/

18. Essentialism: The Disciplined Pursuit of Less. 1st Ed. McKeown G, editor. New York: Random Hours Company; 2014.

19. Marwick TH. Can we justify the cost of echocardiography? Lessons from outcomes research. Eur J Echocardiogr. 2005;6(3):155-163.

20.Kasner M, Westermann D, Steendijk P, Gaub R, Wilkenshoff U, Weitmann K, et al. Utility of Doppler echocardiography and tissue Doppler imaging in the estimation of diastolic function in heart failure with normal ejection fraction: a comparative Doppler-conductance catheterization study. Circulation. 2007;116(6):637-647.

21. Mahadevan VS, Earley M, McClements B. Open access echocardiography has diagnostic yield similar to outpatient echocardiography and is highly rated by general practitioners and patients. Int J Cardiol. 2005;99(3): 389-393. 
22. Corrado D, Basso C, Pavei A, Michieli P, Schiavon M, Thiene G. Trends in sudden cardiovascular death in young competitive athletes after implementation of a preparticipation screening program. JAMA. 2006;296(13):1593-601.

23. O'Connor DP, Knoblauch MA. Electrocardiogram testing during athletic preparticipation physical examinations. J Athl Train. 2010; 45(3): 265-272.

24. Galasko GI, Barnes SC, Collinson P, Lahiri A,Senior R. What is the most cost-effective strategy to screen for left ventricular systolic dysfunction: natriuretic peptides, the electrocardiogram, handheld echocardiography, traditional echocardiography, or their combination? Eur Heart J. 2006;27(2):193-200.

25. Halkin A, Steinvil A, Rosso R, Adler A, Rozovski U and Viskin S. Preventing sudden death of athletes with electrocardiographic screening: what is the absolute benefit and how much will it cost? J Am Coll Cardiol. 2012; 60(22): 2271-2776.

26. Drezner JA, Fischbach P, Froelicher V, Marek J, Pelliccia A, Prutkin JMet al. Normal electrocardiographic findings: recognising physiological adaptations in athletes. Br J Sports Med. 2013;47(3):125-136.

27. Steinvil A, Chundadze T,ZeltserD, etal. Mandatoryelectrocardiographic screening of athletes to reduce their risk for sudden death proven fact or wishful thinking? J Am Coll Cardiol. 2011; 57(11): 1291-6.

28. Spencer KT, Kimura BJ, Korcarz CE, Pellikka PA, Rahko P, Siegel RJ, et al. Focused cardiac ultrasound: recommendations from the American Society of Echocardiography. J Am Soc Echocardiogr. 2013; 26(6):567581

29. Maron BJ, Friedman RA, Kligfield P, Levine BD, Viskin S, Chaitman BR, et al. Assessment of the 12-lead electrocardiogram as a screening test for detection of cardiovascular disease in healthy general populations of young people (12-25 years of age): a scientific statement from the American Heart Association and the American College of Cardiology. J Am Coll Cardiol. 2014;64(14):1479-1514.

30. Pratini N. How Much Does an Echocardiogram Cost? [updated May 19, 2014; cited 2015 April 18]; Available from: http://www. nerdwallet.com/blog/health/2014/05/19/how-much-does-anechocardiogram-cost/3/.

31. Kimura BJ, Blanchard DG, Willis CL, DeMaria AN. Limited cardiac ultrasound examination for cost-effective echocardiographic referral. J Am Soc Echocardiogr. 2002;15(6):640-646.

32. Trambaiolo P, Papetti F, Posteraro A, Amici E, Piccoli M, Cerquetan $\mathrm{E}$, et al. A hand-carried cardiac ultrasound device in the outpatient cardiology clinic reduces the need for standard echocardiography. Heart. 2007;93(4):470-475.

33. Teske AJ, Prakken NH, De Boeck BW, Velthuis BK, Doevendans PA, Cramer MJ. Effect of long term and intensive endurance training in athletes on the age related decline in left and right ventricular diastolic function as assessed by Doppler echocardiography. Am J Cardiol. 2009;104(8):1145-1151.

34. Smith M, Halvorson G, Kaplan G. What's needed is a health care system that learns: recommendations from an IOM report. Jama. 2012;308(16):1637-1638.

35. Kitano H. Computational systems biology. Nature. 2002; 420(6912): 206-210.

36. Lipsitz LA. Understanding health care as a complex system: the foundation for unintended consequences. Jama. 2012;308(3):243244.
37. Weidenbener EJ, Krauss MD, Waller BF, Taliercio CP. Incorporation of screening echocardiography in the preparticipation exam. Clin J Sport Med. 1995;5(2): 86-89.

38. Redfield MM, Jacobsen SJ, Burnett JC Jr, Mahoney DW, Bailey KR, Rodeheffer RJ. Burden of systolic and diastolic ventricular dysfunction in the community: appreciating the scope of the heart failure epidemic. JAMA. 2003; 289(2):194-202.

39. Tsang TS, Barnes ME, Gersh BJ, Takemoto Y, Rosales AG, Bailey KR, et al. Prediction of risk for first age-related cardiovascular events in an elderly population: the incremental value of echocardiography. J Am Coll Cardiol. 2003; 42(7): 1199-1205.

40. Maron BJ, Doerer JJ, Haas TS, Tierney DM, Mueller FO. Sudden deaths in young competitive athletes: analysis of 1866 deaths in the United States, 1980-2006. Circulation. 2009;119(8):1085-1092.

41. Wood MJ, Picard MH. Utility of echocardiography in the evaluation of individuals with cardiomyopathy. Heart. 2004;90(6):707-712.

42. Platz E, Solomon SD. Point-of-care echocardiography in the accountable care organization era. Circ. 2012; 5(5): 676-682.

43. Weiner RB, Wang F, Hutter AM Jr, Wood MJ, Berkstresser $\mathrm{B}, \mathrm{McClanahan} \mathrm{C}$, et al. The feasibility, diagnostic yield, and learning curve of portable echocardiography for out-of-hospital cardiovascular disease screening. J Am Soc Echocardiogr. 2012;25(5):568-575.

44. Wyman RA, Chiu RY, Rahko PS. The 5-minute screening echocardiogram for athletes. J Am Soc Echocardiogr. 2008;21(7):786-788.

45. Lusis AJ, Weiss JN. Cardiovascular networks: systems-based approaches to cardiovascular disease. Circulation. 2010; 121(1): 157170.

46. Khunti K. Systematic review of open access echocardiography for primary care. Eur J Heart Fail. 2004;6(1):79-83.

47.Singh S, Bansal M, Maheshwari P, Adams D, Sengupta SP, Price R, et al. American Society of Echocardiography: Remote Echocardiography with Web-Based Assessments for Referrals at a Distance (ASEREWARD) Study. J Am Soc Echocardiogr. 2013;26(3):221-233.

48. Kahneman D. Thinking, Fast and Slow. 1st Ed. New York: Farrar, Straus and Giroux; 2011.

49. Bishop MA, Trout JD. 50 Years of Successful Predictive Modeling Should be Enough: Lessons for Philosophy of Science. Philosophy of Science. 2002; S197-S208.

50. Goertzel B, Pennachin C , Artificial General Intelligence. editors. Berlin Heidelberg: Springer-Verlag; 2010.

51. Maron BJ and Zipes DP. Introduction: Eligibility recommendations for competitive athletes with cardiovascular abnormalities -- general considerations. J Am Coll Cardiol. 2005;45(8):1318-1321.

52. Maron BJ, Thompson PD, Ackerman MJ, Balady G, Berger S, Cohen D, et al. Recommendations and considerations related to preparticipation screening for cardiovascular abnormalities in competitive athletes: 2007 update. A scientific statement from the American Heart Association Council on Nutrition, Physical Activity, and Metabolism: endorsed by the American College of Cardiology Foundation. Circulation. 2007;115(12):1643-1455.

53. Pellikka PA, Douglas PS, Miller JG, Theodore P, Rolf Baumann, Dennis B. Buxton, et al. American Society of Echocardiography Cardiovascular Technology and Research Summit: a roadmap for 2020. J Am Soc Echocardiogr. 2013;26(4):325-338.

54. Cohen J and Stewart I. The Collapse of Chaos: Discovering Simplicity in a Complex World. Penguin Adult; 2000 
55. Sebastian-Leon P, Vidal E, Minguez P, Conesa A, Tarazona S, Amadoz A, et al. Understanding disease mechanisms with models of signaling pathway activities. BMC. 2014; 8(1):121.

56. Loscalzo J, Kohane I, Barabasi AL. Human disease classification in the postgenomic era: a complex systems approach to human pathobiology. Mol Syst Biol. 2007; 3124.

57. Hood L and Flores M. A personal view on systems medicine and the emergence of proactive $\mathrm{P} 4$ medicine: predictive, preventive, personalized and participatory. N Biotechnol. 2012; 29(6): 613-624.

58. Guyon I, Aliferis C, Cooper G, André E, Jean-P P, Peter S, et al. Lawrence Ns. Design and Analysis of the Causation and Prediction Challenge. JMLR: Workshop and Conference Preceedings; 2008.

59. Melduni RM, Suri RM, Seward JB, Bailey KR, Ammash NM, Oh JK, et al. Diastolic dysfunction in patients undergoing cardiac surgery: a pathophysiological mechanism underlying the initiation of new-onset post-operative atrial fibrillation. J Am Coll Cardiol. 2011;58(9):953961.

60. Popovic D, Ostojic MC, Petrovic M, Vujisic-Tesic B, Popovic B, Nedeljkovic, et al. Assessment of the left ventricular chamber stiffness in athletes. Echocardiography. 2011;28(3):276-287.

61. Seward JB. Physiological aging: window of opportunity. JACC Cardiovasc Imaging. 2011;4(3):243-245.

62. Nagueh SF, Bachinski LL, Meyer D, Hill R, Zoghbi WA, Tam JW, et al Tissue Doppler imaging consistently detects myocardial abnormalities in patients with hypertrophic cardiomyopathy and provides a novel means for an early diagnosis before and independently of hypertrophy. Circulation. 2001;104(2): 128-130.

63. Lewis JF, Spirito P, Pelliccia A, Maron BJ. Usefulness of Doppler echocardiographic assessment of diastolic filling in distinguishing "athlete's heart" from hypertrophic cardiomyopathy. British Heart Journal. 1992; 68(3): 296-300.

64. D’Andrea A, D'Andrea L, Caso P, Scherillo M, Zeppilli P, Calabro R. The usefulness of Doppler myocardial imaging in the study of the athlete's heart and in the differential diagnosis between physiological and pathological ventricular hypertrophy. Echocardiography. 2006; 23(2): 149-157.

65. Menon SC, Eidem BW, Dearani JA, Ommen SR, Ackerman MJ and Miller D. Diastolic dysfunction and its histopathological correlation in obstructive hypertrophic cardiomyopathy in children and adolescents. J Am Soc Echocardiogr. 2009;22(12):1327-1334.

66. Nagueh SF, Appleton CP, Gillebert TC, Marino PN, Oh JK, Smiseth $\mathrm{OA}$, et al. Recommendations for the evaluation of left ventricular diastolic function by echocardiography. J Am Soc Echocardiogr. 2009;22(2):107-133.

67. Klein AL, Hatle LK, Taliercio CP, Taylor CL, Kyle RA, Bailey KR, et al. Serial Doppler echocardiographic follow-up of left ventricular diastolic function in cardiac amyloidosis. J Am Coll Cardiol. 1990;16(5):11351141.

68. Chinnaiyan KM, Alexander D, Maddens M, McCullough PA. Curriculum in cardiology: integrated diagnosis and management of diastolic heart failure. Am Heart J. 2007;153(2):189-200.

69. Cheung YF, Penny DJ, Redington AN. Serial assessment of left ventricular diastolic function after Fontan procedure. Heart. 2000; 83(4): 420-424.

70. Nogueira KC, Furtado M, Fukui RT, Correia MR, Dos Santos RF, Andrade $\mathrm{JL}$, et al. Left ventricular diastolic function in patients with type 2 diabetes treated with a dipeptidyl peptidase- 4 inhibitor- a pilot study. Diabetol Metab Syndr. 2014;6(1):1758-5996.

71. Chen EP, Craig DM, Bittner HB, Davis RD, Van Trigt P. Pharmacological strategies for improving diastolic dysfunction in the setting of chronic pulmonary hypertension. Circulation. 1998; 97(16): 1606-1612.

72. Minhas R. Eminence-based guidelines: a quality assessment of the second Joint British Societies' guidelines on the prevention of cardiovascular disease. Int J Clin Pract. 2007;61(7):1137-1144.

73. Fani Marvasti F, Stafford RS. From sick care to health care-reengineering prevention into the U.S. system. $\mathrm{N}$ Engl $\mathrm{J}$ Med. 2012;367(10): 889-891.

74. Sharma S, Merghani A, Gati S. Cardiac screening of young athletes prior to participation in sports: difficulties in detecting the fatally flawed among the fabulously fit. JAMA Intern Med. 2015;175(1): 125127.

75. Dallal GE. The Little Handbook of Statistical Practice. [updated 2007 Aug 8; cited 2014 Oct 8]; Available from: http://www.jerrydallal. com/lhsp/LHSP.HTM

76. Baggish AL, Wood MJ. Athlete's heart and cardiovascular care of the athlete: scientific and clinical update. Circulation. 2011;123(23):27232735 .

77.Grenny J, Patterson K, Maxfield D, McMillan R, Switzler A. Influencer: The New Science of Leading Change. Columbus: McGraw Hill Education; 2013.

78. Ha JW, Lulic F, Bailey KR, et al. Effects of treadmill exercise on mitral inflow and annular velocities in healthy adults. Am J Cardiol. 2003;91(1):114-115. 